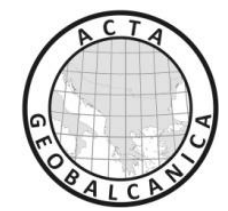

\title{
A 85-YEAR-PERIOD STUDY OF EXTREME PRECIPITATION RECORDS IN THESSALONIKI (GREECE)
}

\author{
Nikoletta Pakalidou ${ }^{1} \&$ Petroula Karacosta ${ }^{2}$ \\ ${ }^{1}$ School of Chemical Engineering and Analytical Science, The University of Manchester, \\ Manchester, United Kingdom \\ ${ }^{2}$ Department of Physics, Aristotle University of Thessaloniki, Thessaloniki, Greece \\ Corresponding author: nikoletta.pakalidou@manchester.ac.uk
}

\begin{abstract}
Precipitation is one of the most important and interesting variables for a country characterized by Mediterranean climate, such as Greece, as it helps to determine the profile of energy balance into the region. For this purpose, the study of distribution of precipitation records is the objective of this work, with annual, monthly and daily rainfall measurements obtained at the Meteorological Station of the Department of Meteorology and Climatology of the Aristotle University of Thessaloniki in Greece. Taking into consideration the climatic change effect upon precipitation regimes, extreme daily rainfall values are statistically analyzed with extreme value statistical methodologies, in order to define the extreme precipitation probability distributions. The region of this study is Thessaloniki, the second biggest city in Greece located at the northern part of it. In order to define the extreme precipitation probability distributions in Thessaloniki for a statistically acceptable time series, the rainfall values refer to the period 1931-2015. The resulted probability distributions could potentially contribute in the prediction of extreme rainfall events, and be used for future climatic change projections. Moreover, based upon the adopted probability distributions, return periods for different precipitation extreme values have been calculated.
\end{abstract}

Keywords: Statistical analysis, precipitation, extreme probability distribution, Thessaloniki (Greece).

\section{INTRODUCTION}

Greece is characterized by a diverse local geomorphology and geography, with a combination of mountains, valleys and beaches throughout the country. This morphology influences the climate of Greek towns, but in general the climatic type of Greece is known as Mediterranean type (Csa). Precipitation is one of the most important variables in order to analyze climatic data and this can be attempted if there is availability of long time series of rainfall data. It is understood that the interest of meteorologists is focused on heavy floods in large cities. One characteristic event was observed on November $2^{\text {nd }} 1977$ in Athens, as 38 deaths were noted [1]. For this purpose, studying the precipitation's records is more than important in order to output the rainfall's profile of a region and to predict extreme rainfall events for both economic and social reasons. At the same time, heavy precipitation over most areas will be frequent as SRES scenarios of IPCC indicate for the $21^{\text {st }}$ century. The last boosts the 
society's interest in a prediction of extreme rainfall events, as the public is interested in climate changes results [2][3][4][5][6].

It is known that extreme events, such as extreme precipitation records, occur on a small, temporal and local scale. So, the objective of this work is to analyze the extreme daily rainfall values in Thessaloniki-the second in population biggest city in Greece located at the northern part of it-during the period 1931-2015. The data are analyzed in order to identify and detect the extreme heights of precipitation. Then the heavy daily rainfalls are examined and studied. The ultimate goal is met through the use of Extreme Value Statistic's methodologies, deriving thus the extreme probabilities distributions for the extreme daily records during the examined period. These distributions are focused on extreme and rare precipitation events, using three types of parameters; location, scale and shape. The probability distributions are mapped out and the results could potentially contribute in the prediction of extreme rainfall events.

\section{DATA AND METHODOLOGY}

The data used in this study are annual, seasonal, and daily measurements of precipitation, obtained at the Meteorological Station of the Department of Meteorology and Climatology of the Aristotle University of Thessaloniki for the 85-year period (1931-2015). For the purpose of this study, an extreme precipitation record was formed by establishing a threshold of $30 \mathrm{~mm} /$ day [7] on the above mentioned dataset. Thus, the data set of this study consists of the daily rainfall events that exceed or are equal to 30 $\mathrm{mm}$, while daily rainfall events less than the threshold value are ignored. Hence, the extreme precipitation record of the study consists of a total of 140 extreme precipitation events throughout the 85 years of the study period.

Regarding the analysis of the data set, statistical methods, such as the 11-year moving average and the Mann Kendal $(M-K)$ [8][9] test, were applied in order to determine and describe the profile of the extreme precipitation record's trend fluctuation. Furthermore, goodness-of-fit $(G O F)$ tests were performed in order to identify, on a theoretical level, and to calculate the probability distribution of the extreme value record. Finally, using the existing data, projections were made in order to calculate the return periods and future events, based on statistical characteristics of the records.

More specifically, the 11-year moving average, along with the $M-K$ test, is used in order to detect changes in the precipitation record. The $M-K$ test indicates the existence of an increasing or decreasing trend during the time series. This is achieved by comparing the null hypothesis $\left(H_{0}\right)$, where no trend exists, as the data are random and independent, with the alternative one $\left(H_{1}\right)$, where a trend is present. The value of $Z$ indicates the significance of the trend; if $Z>Z_{\alpha / 2}$, where $\alpha$ is the chosen significant level (for example, for significant level $5 \%, Z_{0.025}=1.96$ ), the $H_{0}$ hypothesis derives to a significant upward/downward trend [4].

The extreme precipitation record, consisting of 140 events, was tested through three goodness-of-fit tests, namely Kolmogorov-Smirnov $(K-S)$, Anderson-Darling $(A-D)$ and Chi-Squared $\left(X^{2}\right)$ [10], in order to measure the compatibility of this data set to a total of sixty statistical distributions in order to detect the best fitted probability distribution. This is achieved by measuring the compatibility of the given data set with the theoretical functions of the probability distributions, all this by comparing the null hypothesis $\left(H_{0}\right)$, where the data set follows a specific distribution, to the alternative one 
$\left(H_{1}\right)$, where it does not follow a specific distribution. In each one of the three tests, the probability distributions were ranked, and the distribution ranked first was pointed out, based on the minimum statistic value of each test. Among the three identified probability distributions, the best fitting one is defined as the one with the minimum absolute deviation between actual and estimated values, produced by generating random numbers from the parameters of the three prevailing probability distributions.

Furthermore, it is of utmost importance to derive the return periods (recurrence interval) of extreme rainfall events, based on the already existing extreme precipitation record. Thus, if $n$ is defined as the total number of values and $m$ is defined as the rank of each value in a decreasing mode, the probability of the $m^{\text {th }}$ value, $x_{m}$, is calculated as follows; $P\left(x>x_{m}\right)=\frac{m}{n}$ while the return period $T$ is calculated as follows; $P\left(x>x_{T}\right)=\frac{1}{T}$ where $x_{T}$ is the return level [11].

\section{RESULTS}

The annual rainfall time series for the 85-year period is shown in Figure 1. The linear trend was plotted in the time series, but it did not keep on during the whole period, because of the low coefficient of determination. The basic statistical analysis indicated that the annual mean, the standard deviation, and the coefficient of variation were: 465.0 $\mathrm{mm}, 106.0 \mathrm{~mm}$, and $22.8 \%$, respectively. In addition, it is important to highlight the two maximum of annual records observed in 1987 and 2014, with the precipitation reaching the values of $650.4 \mathrm{~mm}$ and $912.2 \mathrm{~mm}$, respectively. They represent the second and the first annual rainfall records for the examined station of Thessaloniki, since the 1892. On the other hand, it is worth mentioning the three significant lower values, remarked in 1932, 1977, and 2000.

In order to filter the short-term precipitation fluctuations, the 11-year moving average method was adopted and the oscillation on rainfall values during the study period is shown in Figure 2. Namely, the three highest and two lowest points indicated the maximum and minimum rainfall values, separating the 85 -year period into five either short, or long, periods with upward and downward trends (applying the $M-K$ test in these periods, positive, negative, significant, or non-significant trends will be discussed). A short first increasing trend was observed from 1937 to 1940, and a short first decreasing was remarked from 1940 to 1943. Subsequently, a positive trend was noticed from 1943 to 1967. The interest in Figure 2 is focused on the period after 1969, when a decreasing trend was noticed until 1996. After that point, a positive trend was calculated until the end of the study period. The most important is that the last two periods (1969-1996 and 1996-onwards) were characterized by steep slopes of curves, negative and positive, respectively. The last increasing trend from 1996 onwards could be reflected by the extreme rainfall record in 2014, where the height of precipitation for this year was the all-year precipitation record, reaching the value of $912 \mathrm{~mm}$. 


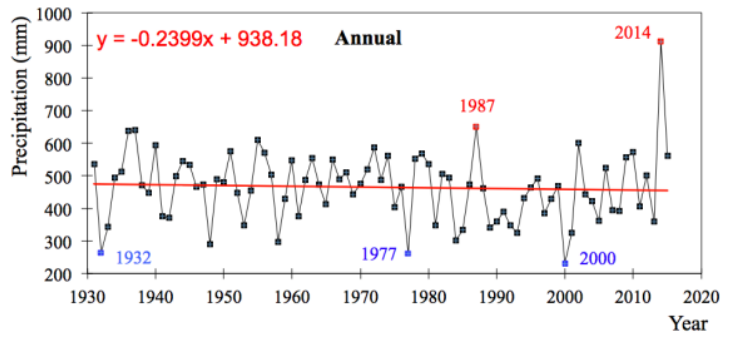

Fig. 1. Time series of annual precipitation in Thessaloniki for the period 1931-2015. The red line indicates the trend of data.

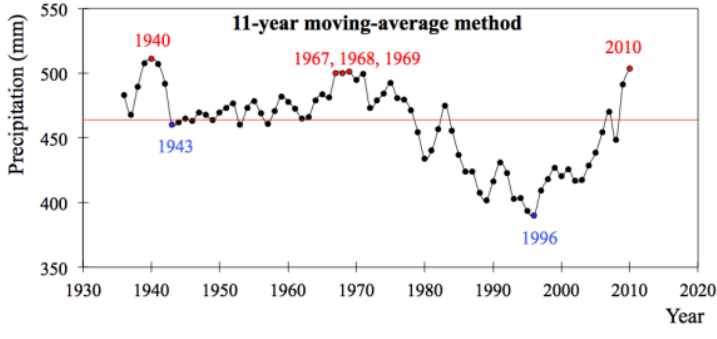

Fig. 2. The 11-year moving average of the annual precipitation in Thessaloniki for the period 1931-2015.

The 10- and 12- year averages of annual records were plotted considering the percentage departures from the mean value ( $c f$ Fig. 3). There were nine and seven periods of 10- and 12- year averages. These diagrams provided positive and negative percentages, as they were characterized as wet and dry periods, respectively. Indeed, one could notice that negative percentages stood out at total. More detailed description should indicate that the last period in 10-year study, 2010-2015, provided an extreme high percentage (almost 10.0\%). In contrast, the last period (2003-2015) for the 12-year average study pointed out less positive percentage than the above period. This is understood if one considers that the last five years in the study period could be characterized by very high rainfall values; two years of them had greater than $550 \mathrm{~mm}$ and 2014 greater than $900 \mathrm{~mm}$.
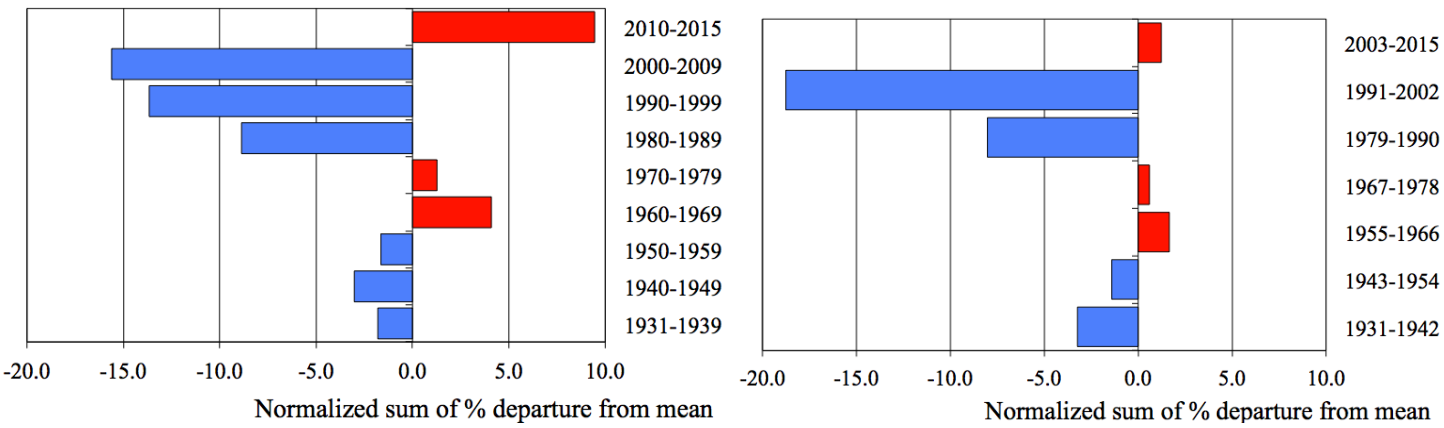

Fig. 3. 10-year (Left) and 12-year (Right) normalized sum of percentage departure from long term-mean for the period 1931-2015 of annual precipitation data in Thessaloniki. Red and blue columns indicate a positive and a negative percentage departure from mean, respectively.

The daily data of precipitation during the study period were analyzed and filtered, and records with values greater than or equal to $30 \mathrm{~mm}$ were distinguished into five groups according to the interval of rainfall values and they are presented in Figure 4. The most interesting was noticed in the interval with height $\geq 60.0 \mathrm{~mm}$, and especially in the highest records during the 85 -year period on the $24^{\text {th }}$ of November in 1985 and $16^{\text {th }}$ of July in 2014, with the daily records reach in $98.0 \mathrm{~mm}$ and $107.3 \mathrm{~mm}$, respectively.

Furthermore, the daily precipitation data were organized into regular seasons and agricultural seasons (agro-). The last was necessary, as Greece is an agricultural country and the knowledge of dry and wet periods is extreme important for the cultivation of lands. To this end, the twelve months are grouped into four agro-seasons as indicated by 
Karacostas and Pennas [12] that are: agro-spring: Apr, May, agro-summer: Jun, Jul, Aug, Sep, agro-autumn: Oct, Nov, agro-winter: Dec, Jan, Feb, Mar. For the daily rainfall, the threshold of $30 \mathrm{~mm}$ was considered for the above periods, and the results were plotted in Figure 5. The maximum number of days with heights $\geq 30 \mathrm{~mm}$ was noticed in autumn (52 days) and in agro-summer (51 days). In contrast, the minimum number of days above the threshold was remarked in spring (26 days) and in agrospring (17 days). These are probably due to the relocation of the months of March and September.

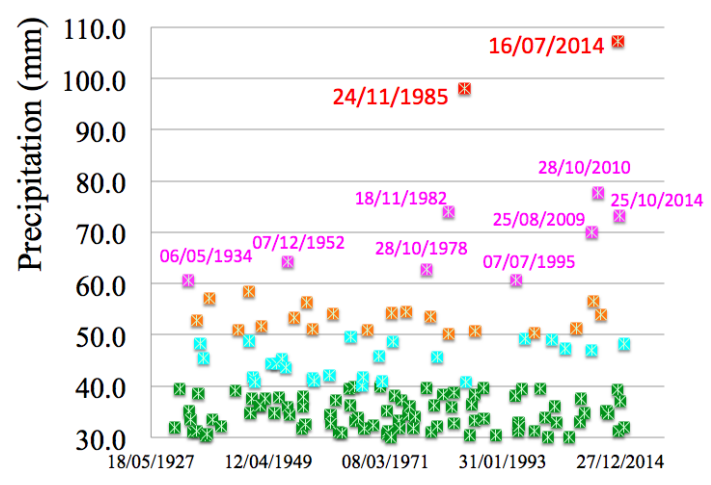

Fig. 4 . The 140 cases with daily precipitation $\geq$ $30 \mathrm{~mm} /$ day for the period 1931-2015 in Thessaloniki. The colors correspond to the individual intervals of $\mathrm{mm} /$ day; green: $30 \leq$ $x<40$, cyan: $40 \leq x<50$, orange: $50 \leq x<60$, pink: $60 \leq x<90$, red: $x \geq 90$.

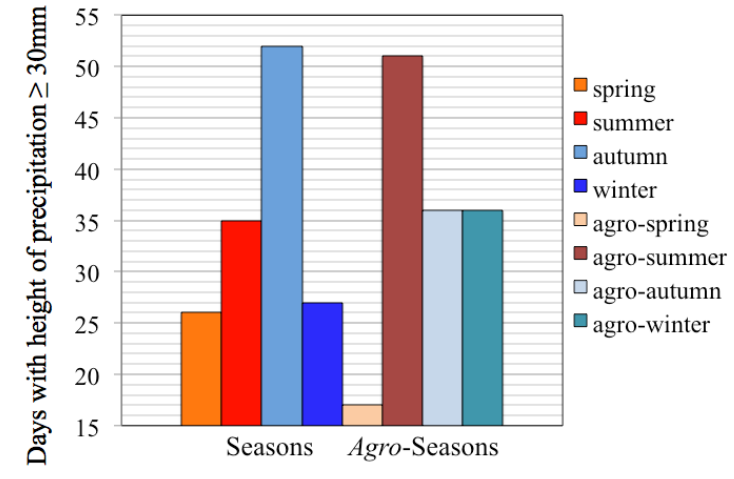

Fig. 5. The 140 cases with daily precipitation $\geq 30 \mathrm{~mm} /$ day in groups of seasons and agroseasons for the period 1931-2015 in Thessaloniki.

The study is statistically fulfilled performing the $M-K$ test and the Extreme Value Statistics for the 85-year period in Thessaloniki. The $M-K$ test described upwards and downwards trends for annual, seasonal, and agro-seasonal periods. The Table 1 was completed by incorporating the standard deviations and correlation coefficients for each group described earlier. One could notice that $S$ and $Z$ parameters are positive only for spring, agro-spring, and agro-summer, indicating an upward trend. In general, there is no statistically significant trend for the whole period at a $95 \%$ confidence level. In addition, correlation coefficient provides results for the degree of contribution of each season, regular and agricultural, to the mean annual precipitation. In Table 1, one could see that, in case of regular seasons, autumn contributed more in the mean annual rainfall and winter less, as the correlation coefficients were $r=0.64$ and $r=0.28$, respectively. Further, during the agricultural season, agro-winter presented the highest coefficient ( $\mathrm{r}$ $=0.60)$ and agro-spring the lowest one $(\mathrm{r}=0.21)$. 
Table 1. Results for statistical tests for the annual, seasonal and agro-seasonal periods in 19312015 in Thessaloniki.

\begin{tabular}{llllllllll}
\hline & $\begin{array}{l}\text { Mean } \\
(\mathbf{m m})\end{array}$ & $\begin{array}{l}\text { Std } \\
(\mathbf{m m})\end{array}$ & $\begin{array}{l}\mathbf{C V} \\
(\boldsymbol{\%})\end{array}$ & $\begin{array}{l}\text { Cor. } \\
\text { with } \\
\text { annual }\end{array}$ & $\begin{array}{l}\text { Low } \\
\text { value }\end{array}$ & $\begin{array}{l}\text { High } \\
\text { value }\end{array}$ & $\begin{array}{l}\text { M-K } \\
(\text { tau })\end{array}$ & $\begin{array}{c}\text { M-K } \\
(\mathbf{S})\end{array}$ & $\begin{array}{l}\text { M-K } \\
(\mathbf{Z})\end{array}$ \\
\hline Annual & 465.0 & 106.0 & 22.8 & no & 230.8 & 912.2 & -0.089 & -317 & -1.199 \\
Spring & 122.9 & 43.5 & 35.4 & 0.45 & 24.1 & 243.9 & 0.020 & 73 & 0.273 \\
Summer & 83.2 & 45.6 & 54.8 & 0.54 & 11.4 & 245.8 & -0.017 & -61 & -0.228 \\
Autumn & 131.8 & 54.4 & 41.2 & 0.64 & 17.0 & 262.8 & -0.003 & -11 & -0.038 \\
Winter & 126.3 & 57.4 & 45.4 & 0.28 & 6.8 & 285.6 & -0.066 & -236 & -0.892 \\
Agro-Spring & 84.2 & 37.5 & 44.5 & 0.21 & 20.3 & 166.9 & 0.016 & 57 & 0.213 \\
Agro-Summer & 115.7 & 58.3 & 50.4 & 0.58 & 11.6 & 346.4 & 0.030 & 108 & 0.406 \\
Agro-Autumn & 99.3 & 48.4 & 48.8 & 0.53 & 8.8 & 225.2 & -0.092 & -329 & -1.245 \\
Agro-Winter & 165.8 & 64.9 & 39.1 & 0.60 & 52.7 & 361.9 & -0.050 & -177 & -0.668 \\
\hline
\end{tabular}

The 140 extreme daily precipitation cases identified for the examined period were used as input information into sixty statistical distributions in order to detect the best fitted probability distribution. Following the study, the Kolmogorov-Smirnov $(K-S)$, the Anderson-Darling $(A-D)$, and the Chi-Squared $\left(X^{2}\right)$ tests were applied as GOF distribution to the data. The results of the best fitted extreme probability distribution for the 140 daily cases are presented in Table 2 and depicted in Figure 6. Studying Table 2, it is well understood that the Generalize Pareto distribution is indicated as the best fitted distribution for the 140 cases with precipitation $\geq 30 \mathrm{~mm} /$ day.

Table 2 . The fitted distributions for the 140 cases with daily precipitation $\geq 30 \mathrm{~mm} /$ day for the period 1931-2015 in Thessaloniki. The best fitted probability distribution is the Generalized Pareto distribution.

\begin{tabular}{llll}
\hline Test & Distribution & Statistic & Parameters \\
\hline $\boldsymbol{K}-\boldsymbol{S}$ & Gen. Pareto & 0.0461 & $\mathrm{k}=0.047, \sigma=11.28, \mu=29.992$ \\
$\boldsymbol{A}-\boldsymbol{D}$ & Jonson SB & 0.3380 & $\gamma=2.822, \delta=1.00, \lambda=161.07, \xi=28.818$ \\
$\boldsymbol{X}^{2}$ & GEV & 5.2348 & $\mathrm{k}=0.269, \sigma=6.36, \mu=35.887$ \\
\hline
\end{tabular}

Using the aforementioned extreme probability distributions, the projections in return periods about the extreme precipitation records could be made. So, the return periods of events could be predicted using theoretical distributions, based on historical data (observations). The frequency of the extreme events to re-occur is plotted in Figure 7. One could observe that the highest encountered daily precipitation record of $107.3 \mathrm{~mm}$ could be re-occurred in 280 years. Moreover, the return period for the second daily precipitation record of $98.0 \mathrm{~mm}$ is once every 93 years. Figure 7 could be a very useful tool for future developments within the major area of Thessaloniki. 

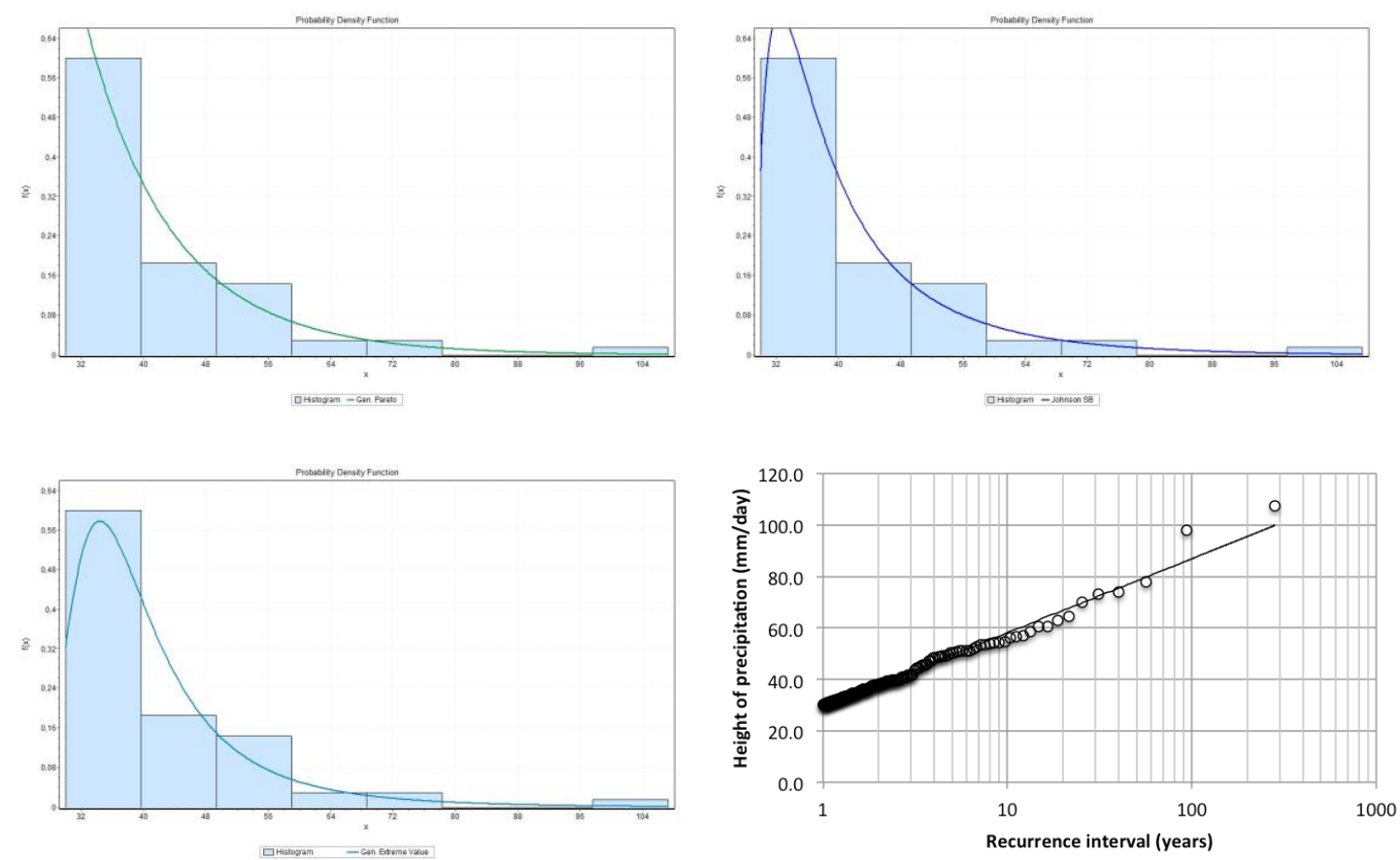

Fig. 6. The Gen. Pareto/Kolmogorov-Smirnov (up-left), the Johnson SB/Anderson-Darling (up-right), and the $G E V / X^{2}$ (down-left) fit to the

Fig. 7. Frequency of the extreme events of precipitation records to re-occur in Thessaloniki. 140 cases with $\geq 30 \mathrm{~mm} /$ day during the period 1931-2015 in Thessaloniki.

\section{CONCLUSIONS}

The trends of the annual, seasonal, and agro-seasonal precipitation's records were analyzed in Thessaloniki over the 85-year period of 1931-2015. During the study period, in 2014 the annual precipitation measured was extreme high reaching the value of $912.2 \mathrm{~mm}$. This remains the highest annual rainfall record from 1892 in Thessaloniki. The study was extended on the daily basis and the threshold of $30 \mathrm{~mm} /$ day was used in daily records in order to identify extreme precipitation events to apply the extreme value statistical methodologies. Indeed, there were two extreme records, during the last 85 years, in $24^{\text {th }}$ of November in $1985(98.0 \mathrm{~mm})$ and in $16^{\text {th }}$ of July in $2014(107.3 \mathrm{~mm})$. The last is the highest daily precipitation measured during the last 124 years in Thessaloniki. Further, applying the $\mathrm{M}-\mathrm{K}$ test, positive and negative trends were identified over the study period. There is no statistically significant trend for the whole period at a 95\% confidence level. More specific, there were positive trends only for spring, agro-spring, and agro-summer.

Moreover, the Generalized Pareto probability distribution was indicated as the best fitted distribution for the 140 cases above the threshold of $30 \mathrm{~mm} /$ day during the last 85 years in Thessaloniki. Using this type of probability, the return periods of the most highly records of $98 \mathrm{~mm}$ and $107.3 \mathrm{~mm}$ were investigated. For this purpose, the height of precipitation was plotted versus re-occurrence intervals, and the line designed is a leader for the return periods discussion. It was shown that the highest daily precipitation record measured at $107.3 \mathrm{~mm}$ can be re-occurred in 280 years, and the return period for the height of $98.0 \mathrm{~mm}$ is once every 93 years. 
It will be a very good idea for a future work if this study is used as a subject to analyze the significant changes before and after the climate change. Also, further studies are needed on monthly basis in order to detect the degree of influence of the monthly records changes in seasonal records.

\section{REFERENCES}

[1] Nikolaidou M and Hadjichristou E. Recording and assessment of flood damages in Greece and Cyprus. Diploma Thesis (in Greek). National Technical University, Athens, Greece, 1995.

[2] Koutsoyiannis D and Baloutsos G. Analysis of a long record of annual maximum rainfall in Athens, Greece, and design rainfall inferences. Natural Hazards. 22:2948, 2000.

[3] Zhang X, Vincent LA, and Hogg WD, Niitsoo A. Temperature and precipitation trends in Canada during the 20th Century. Atmospheric Ocean 38:395-429, 2000.

[4] Partal T and Kahya E. Trend analysis in Turkish precipitation data. Hydrological Processes 20:2011-2026, 2006.

[5] Alexander LV et al. Global observed changes in daily climate extremes of temperature and precipitation. J. Geophys. Res. 111:109, doi:10.1029/2005JD006290, 2006.

[6] Feidas H, Noulopoulou N, Makroyiannis T, and Bora-Senta E. Trend analysis of precipitation time series in Greece and their relation with circulation using surface and satellite data: 1955-2001. Theor Appl Climatol 87:155-177, 2007.

[7] Dauphine A. Les precipitations dans les midis Francais; etude de climatologie inductive. Thesede Doctorat d'Etat. Univ. De Dijon, 783 pp, 1975.

[8] Mann HB. Nonparametric tests against trend. Econometrica 13:245-259, 1945.

[9] Kendall MG. Rank Correlation Methods. Griffin London, UK, 1975.

[10] Yates F. Contingency table involving small numbers and the $\chi 2$ test. Supplement to the Journal of the Royal Statistical Society 1: 217-235, 1934.

[11]Coles S. An Introduction to Statistical Modelling of Extreme Values. SpringerVerlag: London, 2001.

[12] Karacostas TS and Pennas PJ. A comprehensive study of rainfall during the last five consecutive low-rain years. International Conference on Atmospheric Physics., Rome, Italy, 343-346, 1994. 